Article

\title{
Phenol photocatalytic degradation over mesoporous TUD-1-supported chromium oxide-doped titania photocatalyst
}

\author{
Yee Khai Ooi a, Leny Yuliati ${ }^{b}$, Siew Ling Lee ${ }^{a, b, *}$ \\ a Department of Chemistry, Faculty of Science, Universiti Teknologi Malaysia, 81310 Johor Bahru, Johor, Malaysia \\ b Center for Sustainable Nanomaterials, Ibnu Sina Institute for Scientific and Industrial Research, Universiti Teknologi Malaysia, 81310 Johor Bahru, Johor, \\ Malaysia
}

\section{A R T I C L E I N F O}

\section{Article history:}

Received 28 July 2016

Accepted 21 August 2016

Published 5 November 2016

\section{Keywords:}

Phenol

TUD-1

Titania

Photocatalyst

Mesoporous

\begin{abstract}
A B S T R A C T
Mesoporous Technische Universiteit Delft (TUD-1)-supported chromium oxide-doped titania $\left(\mathrm{Cr}-\mathrm{TiO}_{2}\right)$ was developed as a promising photocatalyst for phenol photodegradation under visible light irradiation. Low-angle X-ray diffraction and Fourier transform infrared spectroscopy results confirmed the amorphous and mesoporous silicate framework of TUD-1 in TUD-1-supported $\mathrm{Cr}_{-} \mathrm{TiO}_{2}$. The mesostructure of TUD-1 was further verified via $\mathrm{N}_{2}$ adsorption-desorption analysis, which showed a type-IV isotherm with a narrow average pore size distribution of $3.9 \mathrm{~nm}$ and high surface area of $>490 \mathrm{~m}^{2} / \mathrm{g}$. Transmission electron microscopy analysis results indicated that TUD-1-supported $\mathrm{Cr}^{-} \mathrm{TiO}_{2}$ contained nanoparticles and porous channels. An increase in band gap energy was observed after loading $\mathrm{Cr}-\mathrm{TiO}_{2}$ into TUD-1. Compared with that of unsupported $\mathrm{Cr}-\mathrm{TiO}_{2}$, TUD-1-supported $\mathrm{Cr}_{-} \mathrm{TiO}_{2}$ showed higher photocatalytic activity for phenol degradation under visible light irradiation. The TUD-1 supported $\mathrm{Cr}^{-\mathrm{TiO}_{2}}$ photocatalyst with a Si/Ti molar ratio of $30 \mathrm{ex}-$ hibited the highest photodegradation of phenol (82\%) of the prepared samples. The photodegradation of phenol by the supported catalyst followed the Langmuir adsorption isotherm with first-order kinetics.
\end{abstract}

(C) 2016, Dalian Institute of Chemical Physics, Chinese Academy of Sciences. Published by Elsevier B.V. All rights reserved.

\section{Introduction}

The large scale of chemical industry and excessive use of chemicals form numerous types of wastewater that are possibly hazardous to the environment and human body [1]. Wastewater that contains phenolic compounds has been one of the foremost pollution problems for decades. Phenolic compounds are persistent toxic pollutants that can enter wastewater streams from a variation of industries; for example, steel, resins, ceramics, fiber glass, fungicides, herbicides, metals, and textiles [2]. Although phenol is reasonably easy to biodegrade, conventional biodegradation of phenol is usually ineffective because of a self-inhibitory effect at excessive concen- trations, the accretion of phenolic intermediates, and the discharge of soluble microbial products [3,4]. Even when phenol is biodegraded, the reaction kinetics are sluggish, and biodegradation occurs only at low phenol concentration. In contrast, advanced oxidation processes are effective techniques to break down bulky organic compounds, including aromatic components [5].

Phenol was first synthesized in 1834 by Runge [6], and is currently produced on a sizeable scale of roughly 7 billion $\mathrm{kg}$ per annum from petroleum resources. Phenol is an important starting material in the production of numerous efficacious substances and materials; e.g., polycarbonates, epoxides resins, nylon, and herbicides [7]. Phenol contamination of water

* Corresponding author. Tel: +607-5536039, Fax: +607-5536080, E-mail: sllee@ibnusina.utm.my 
sources has caused horrendous global pollution as a result of these processes because of the large scale of manufacture and high concentration of phenol in wastewater [8]. Phenol has an extremely irritating and carcinogenic nature, and can induce substantial impairment of the respiratory tract and systemic poisoning when it comes into direct or indirect contact with humans.

The typical industrial methods to remove phenol include adsorption, solvent extraction, chemical oxidation, and biological treatment [9]. However, these processes are not cost-effective, yield noxious or undesirable side products, and use hazardous chemicals and solvents in bulky quantities. Photocatalysis is an attractive alternative method to degrade phenol because it is green applied science using an advanced oxidation process that can completely mineralize phenol into small non-hazardous constituents such as $\mathrm{CO}_{2}$ and $\mathrm{H}_{2} \mathrm{O}$.

Titania $\left(\mathrm{TiO}_{2}\right)$ has been widely used as a photocatalyst because of its powerful oxidizing attributes, non-toxicity, low cost and high photostability [10]. However, $\mathrm{TiO}_{2}$ can only perform efficiently under ultraviolet irradiation because of its wide band gap of $3.2 \mathrm{eV}$. The photocatalytic performance of $\mathrm{TiO}_{2}$ can be improved using $\mathrm{TiO}_{2}$ nanoparticles or supported $\mathrm{TiO}_{2}$ instead of bulk $\mathrm{TiO}_{2}$ [11]. Moreover, doping $\mathrm{TiO}_{2}$ with transition metal oxides or nanoparticles improves its photoactivity, and can even enable $\mathrm{TiO}_{2}$ to work under visible light irradiation [12]. Chromium oxide is a suitable dopant to broaden the photoresponse of $\mathrm{TiO}_{2}$ by narrowing its band gap to realize a visible photoresponse [13]. Although doping $\mathrm{TiO}_{2}$ with transition metal oxides has allowed $\mathrm{TiO}_{2}$ to perform under visible light, the low surface area of the resulting materials resulting from agglomeration still continues to be a drawback because it restrains the accessibility of the active sites [14].

A number of silica matrixes with high surface area including silica aerogel and zeolite have been intensively used for use as support materials for $\mathrm{TiO}_{2}$-based photocatalysts $[15,16]$. In this study, the relatively new silica matrix Technische Universiteit Delft (TUD-1) is used as a support material for chromium oxide-doped $\mathrm{TiO}_{2}\left(\mathrm{Cr}_{-} \mathrm{TiO}_{2}\right)$ nanoparticles. TUD-1 is amorphous and mesoporous with 3D interlinked pore channels [14]. Unlike silica aerogel, it can be easily produced via a comparatively simple and cost-efficient procedure. Recently, our research group reported the use of TUD- 1 as a support for $\mathrm{TiO}_{2}$ nanoparticles $[17,18]$. The synthesized photocatalysts demonstrated favorable photocatalytic responses in the photodegradation of cationic and anionic dyes. In this work, we examine in detail the properties and photocatalytic activity under visible light irradiation of $\mathrm{Cr}-\mathrm{TiO}_{2}$ supported on TUD-1 ( $\left.\mathrm{Cr}-\mathrm{TiO}_{2} / \mathrm{TUD}-1\right)$. The kinetic behavior and effect of several reaction parameters on the photocatalytic performance of the supported catalysts are investigated.

\section{Experimental}

\subsection{Photocatalyst synthesis}

$\mathrm{Cr}-\mathrm{TiO}_{2}$ was synthesized via a sol-gel method as described elsewhere [17]. First, a mixture of titanium tetraisopropoxide
(TTIP), ethanol and acetylacetone (acac) as a chelating agent with a TTIP:ethanol:acac molar ratio of 1:100:2 was prepared. All chemicals were of analytical grade with $>99 \%$ purity and were acquired from Sigma-Aldrich. Chromium(III) acetylacetonate was used as a precursor of chromium oxide and dissolved in acac. The chromium oxide dopant $(1 \mathrm{~mol} \%)$ was added dropwise to the TTIP mixture, which was then stirred for $2 \mathrm{~h}$. $\mathrm{Cr}-\mathrm{TiO}_{2}$ was obtained following solvent evaporation at $353 \mathrm{~K}$, drying overnight at $383 \mathrm{~K}$, and calcination at $823 \mathrm{~K}$ for 5 h.

TUD-1 was synthesized as follows. A mixture of water, triethanolamine (TEA, $97 \mathrm{wt} \%$ ), tetraethylammonium hydroxide (TEAOH, $2 \mathrm{~mol} / \mathrm{L}$ in water), and tetraethyl orthosilicate (TEOS, 98 wt\%) with a TEOS/TEA/TEAOH/ $\mathrm{H}_{2} \mathrm{O}$ molar composition of 1:0.5:0.1:11 was stirred for $2 \mathrm{~h}$. The solution was allowed to evaporate under ambient conditions for $24 \mathrm{~h}$ to form a solid gel. The gel was hydrothermally treated at $403 \mathrm{~K}$ for $10 \mathrm{~h}$ in an autoclave. The mixture was dried at $373 \mathrm{~K}$, and subsequently calcined in air at $873 \mathrm{~K}$ for $6 \mathrm{~h}$ to remove the organic components.

To synthesize $\mathrm{Cr}-\mathrm{TiO}_{2} / \mathrm{TUD}-1$, the pre-synthesized $1 \mathrm{~mol} \%$ $\mathrm{Cr}^{-} \mathrm{TiO}_{2}$ nanoparticles were added into a mixture of TUD-1 precursors with different $\mathrm{Si} / \mathrm{Ti}$ molar ratios. The mixture was stirred for $2 \mathrm{~h}$ before aging and evaporation as described above. The resulting samples were denoted as $\mathrm{Cr}_{-\mathrm{TiO}} / \mathrm{TUD}-1(x)$, where $x$ is the $\mathrm{Si} / \mathrm{Ti}$ molar ratio and ranged from 10 to 50. Unsupported $\mathrm{Cr}_{-} \mathrm{TiO}_{2}$ and MCM-41-supported $\mathrm{Cr}_{-} \mathrm{TiO}_{2}\left(\mathrm{Cr}-\mathrm{TiO}_{2} / \mathrm{MCM}-41\right)$ were also synthesized for comparison.

\subsection{Characterization}

Powder X-ray diffraction (XRD) patterns were obtained on a Bruker Advance D8 diffractometer $(40 \mathrm{kV}, 40 \mathrm{~mA})$ fitted with an incident-beam graphite monochromator with $\mathrm{Cu} K_{a}$ radiation $(\lambda=0.154 \mathrm{~nm})$. The step size was $0.0175^{\circ}$, and the counting time per step was $8 \mathrm{~s}$. The samples were scanned over a $2 \theta$ range of $0.2^{\circ}-90^{\circ}$. Fourier transform infrared (FTIR) spectra were recorded on a Nicolet iS10 spectrometer using an attenuated total reflectance accessory.

Nitrogen adsorption-desorption isotherms, surface areas and pore volumes of the samples were measured at $77 \mathrm{~K}$ using a Quantachrome Surface Autosorb-6B sorption analyzer. Samples were pre-treated at $523 \mathrm{~K}$ for $16 \mathrm{~h}$ before these measurements. Pore size distributions were determined from adsorption branched using the Barrett-Joyner-Halenda (BJH) model. The Brunauer-Emmett-Teller (BET) method was used to determine the surface areas of samples, while pore volumes were calculated using the $t$-plot method.

Diffuse-reflectance UV-Vis spectra were measured under ambient conditions on a Perkin Elmer Lambda 35 spectrophotometer using $\mathrm{BaSO}_{4}$ as a reference. Samples were ground carefully and then were scanned in the range of 200-900 nm. Field-emission scanning electron microscopy (FESEM) was conducted at $10 \mathrm{kV}$ on a JEOL JSM-6701F microscope. The surfaces of samples were coated with gold to prevent charging effects. Energy-dispersive X-ray (EDX) analysis was used to 
determine the chemical composition of the samples with a LINK EDX system. Transmission electron microscopy (TEM) was performed with a JEOL JEM-2011 electron microscope operating at $200 \mathrm{kV}$ with a field-emission gun as an electron source and Gatan 794 CCD camera. Samples were prepared on copper-supported carbon polymer grids by immersing a copper grid in a few droplets of a suspension of each ground sample solvated in acetone, followed by drying under ambient conditions. Zeta potential and average particle size analyses were carried out at different $\mathrm{pH}$ via microelectrophoresis using a Malvern Zetasizer.

\subsection{Photocatalytic Activity Testing}

A simple batch-type reactor with a hatch was used to elucidate the photocatalytic activity of the synthesized samples. A 100-mL beaker was used as the photoreactor. The visible light source was a 550-W tungsten halogen lamp with a band around $420 \mathrm{~nm}$ positioned on the top of the reactor. After the photocatalysts reached adsorption equilibrium in the dark, the reactor was irradiated with visible light for $5 \mathrm{~h}$. In an example experimental setup, aqueous phenol solution (200 ppm, $50 \mathrm{~mL}$ ) at $\mathrm{pH}=7$ was stirred at $350 \mathrm{r} / \mathrm{min}$ and photocatalyst $(0.1 \mathrm{~g})$ was added. Aliquots of the solution $(1 \mathrm{~mL})$ were sequestrated at $1 \mathrm{~h}$ intervals, centrifuged and then filtered using a $0.2-\mu \mathrm{m}$ polytetrafluoroethylene Millipore membrane filter to isolate suspended catalyst agglomerates. Finally, each aliquot was analyzed using a Thermo Scientific GENESYS 10S UV-Vis spectrophotometer in the range of $200-800 \mathrm{~nm}$. The concentration of phenol was determined using the $270-\mathrm{nm}$ absorbance peak.

The reusability of selected $\mathrm{Cr}-\mathrm{TiO}_{2} /$ TUD-1( $x$ ) samples was examined. For this purpose, the photocatalyst was filtered after reaction, washed multiple times with distilled water, and subsequently dried at $373 \mathrm{~K}$ for $24 \mathrm{~h}$. After that, the sample was calcined at $723 \mathrm{~K}$ for $4 \mathrm{~h}$. The photocatalyst was resuspended in fresh phenol solution following the steps described above. Photocatalysts were reused up to three times. The reusability of $\mathrm{Cr}_{-} \mathrm{TiO}_{2} / \mathrm{MCM}-41$ was also examined for comparison.

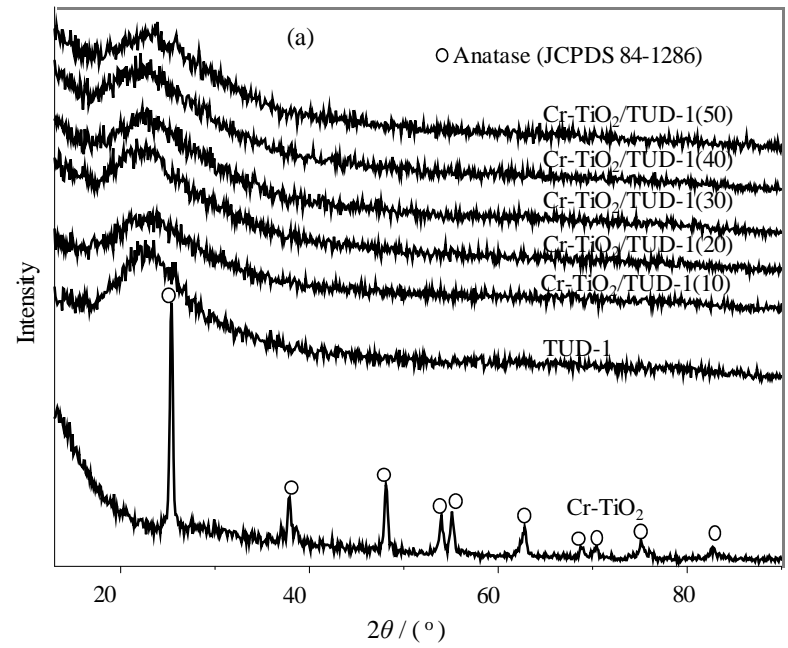

\section{Results and discussion}

\subsection{Properties of the Photocatalysts}

A series of $\mathrm{Cr}_{-1 i O} / \mathrm{TUD}-1(x)$ samples with $x=10,20,30,40$, and 50 were synthesized and characterized. For comparison, unsupported $\mathrm{Cr}-\mathrm{TiO}_{2}$ and TUD-1 were also prepared and characterized. The phase purity and crystallinity of the samples were determined via powder XRD measurements. Fig. 1(a) shows the XRD patterns of $\mathrm{Cr}^{-} \mathrm{TiO}_{2}$, TUD-1, and $\mathrm{Cr}-\mathrm{TiO}_{2}$ /TUD-1. $\mathrm{Cr}_{-} \mathrm{TiO}_{2}$ crystallized in the anatase phase (JCPDS file no. 84-1286). Meanwhile, TUD-1 was amorphous because no peaks were detected in its XRD pattern. A broad halo between $2 \theta=$ $20^{\circ}-40^{\circ}$ was observed, implying the sample contained well-ordered amorphous silica. The amorphous nature of TUD-1 remained after loading $\mathrm{Cr}^{-} \mathrm{TiO}_{2}$. No change of the XRD

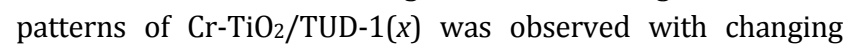
$\mathrm{Si} / \mathrm{Ti}$ molar ratio. This result indicates that $\mathrm{Cr}-\mathrm{TiO}_{2}$ is well dispersed on the surface of TUD-1 or successfully loaded into the TUD-1 framework. Alternatively, the crystalline phases of both $\mathrm{TiO}_{2}$ and $\mathrm{Cr}_{2} \mathrm{O}_{3}$ may not have been detected because of the low $x$ in the $\mathrm{Cr}_{-} \mathrm{TiO}_{2} / \mathrm{TUD}-1(x)$ samples.

Fig. 1(b) depicts low-angle XRD patterns of the samples. TUD- 1 exhibited a high-intensity peak at $2 \theta=2.40^{\circ}$ and three continuous small peaks at $2 \theta=4.02^{\circ}, 4.58^{\circ}$, and $6.22^{\circ}$, which were indexed as (100), (110), (200), and (210), respectively. The most intense peak was that of the (100) reflection, which indicated the mesoporous hexagonal ordering of TUD-1, while the weaker peaks represented the quasi-regular arrangement with hexagonal symmetry of the TUD-1 structure [19]. Similarly, all $\mathrm{Cr}-\mathrm{TiO}_{2} / \mathrm{TUD}-1(x)$ samples exhibited an intense peak at $2 \theta=1.5^{\circ}-3^{\circ}$ accompanied with three small peaks at low angle, signifying the mesostructure characteristics of the synthesized materials [20]. As expected, the peak intensities increased with $x$. Loading of $\mathrm{Cr}-\mathrm{TiO}_{2}$ caused structural deformation of the silicate matrix in TUD-1, lowering its crystallinity. A similar loading effect has also been reported in the literature [21]. The crystallite size of $\mathrm{Cr}-\mathrm{TiO}_{2}$ estimated using the Scherrer equation

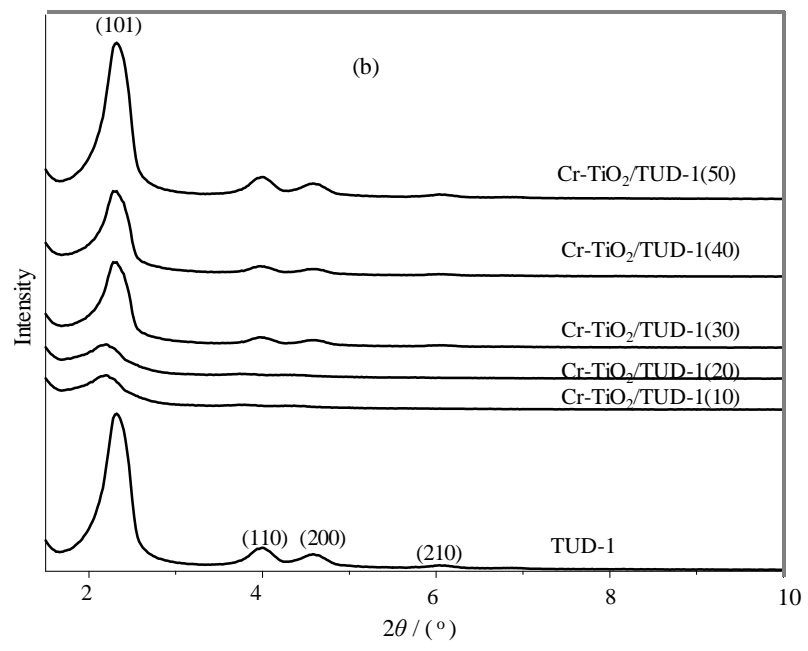

Fig. 1. (a) Wide-angle XRD patterns of $\mathrm{Cr}_{-} \mathrm{TiO}_{2}$, TUD-1 and TUD-1 supported $\mathrm{Cr}-\mathrm{TiO}_{2}$ samples; (b) Small-angle XRD patterns of TUD-1 and TUD-1 supported $\mathrm{Cr}-\mathrm{TiO}_{2}$ samples. 
was $20 \mathrm{~nm}$, implying the formation of nanoparticles. Calculations using Bragg's Law and the (101) peak showed that the $d$-lattice spacing of $\mathrm{Cr}^{-\mathrm{TiO}_{2}}$ was $0.35 \mathrm{~nm}$.

FTIR spectra of $\mathrm{Cr}^{-\mathrm{TiO}_{2}}$, TUD- 1 and $\mathrm{Cr}^{-\mathrm{TiO}_{2}}$ /TUD-1( $x$ ) samples are shown in Fig. 2. For the $\mathrm{Cr}-\mathrm{TiO}_{2}$ sample, a broad peak at $600 \mathrm{~cm}^{-1}$ assigned to the stretching of Ti-O bonds was detected. The band at $1625 \mathrm{~cm}^{-1}$ was attributed to the bending of the $\mathrm{O}-\mathrm{H}$ bonds of silanol groups and adsorbed water [22]. The intensity of this band weakened with increasing Ti content and it also shifted slightly to lower wavenumber, signifying a possible interaction of Ti with TUD-1. A broad band at around 3440 $\mathrm{cm}^{-1}$ was detected for $\mathrm{Cr}-\mathrm{TiO}_{2}$, which was attributed to adsorbed $\mathrm{H}_{2} \mathrm{O}$ molecules. Similar to the band at $1641 \mathrm{~cm}^{-1}$, the intensity of this band increased remarkably with increasing TUD-1 content in the samples. These findings imply that the greater the content of $\mathrm{Cr}-\mathrm{TiO}_{2}$, the fewer hydroxyl groups present on the catalyst surface.

For the TUD-1 and TUD-1-supported samples, bands at 1079,802 and $456 \mathrm{~cm}^{-1}$ attributed to the asymmetric stretching, symmetric stretching and bending vibrations of $\mathrm{Si}-\mathrm{O}-\mathrm{Si}$, respectively, were observed [23]. The presence of $\mathrm{Cr}-\mathrm{TiO}_{2}$ on TUD-1 decreased the intensities of all three bands. In addition, these bands were shifted from their original positions, suggesting perturbation of the silica network because of $\mathrm{Si}-\mathrm{O}-\mathrm{Ti}$ bond formation, which is consistent with the XRD analysis. Furthermore, the intensity of a weak band at $965 \mathrm{~cm}^{-1}$ corresponding to $\mathrm{Si}-\mathrm{O}-\mathrm{H}$ bending increased with $\mathrm{Cr}-\mathrm{TiO}_{2}$ content in the TUD-1-supported samples, which provides further evidence for Si-O-Ti interaction [24].

$\mathrm{N}_{2}$ adsorption-desorption isotherms of the Cr-TiO 2 /TUD-1( $x$ ) photocatalysts are presented in Fig. 3(a). TUD-1 exhibited a type-IV isotherm with an H3-type narrow hysteresis loop. A similar trend was also observed for all the

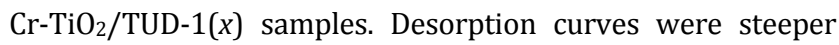
than adsorption curves at relative pressures of approximately 0.4-0.5. This characteristic was attributed to the mass-transfer-limited filling and emptying of non-uniform or incompletely blocked uniform pores. Therefore, these results

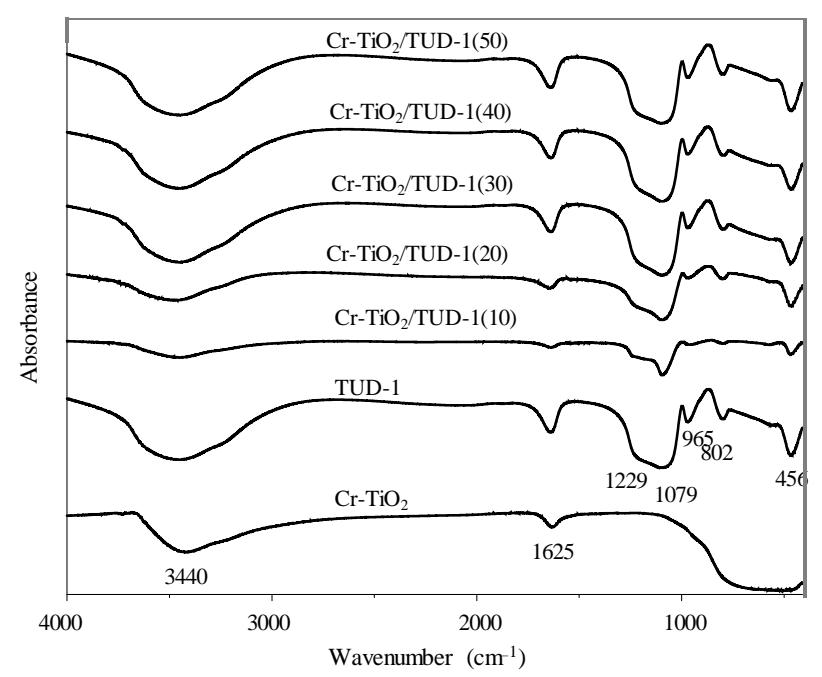

Fig. 2. FTIR spectra of $\mathrm{Cr}-\mathrm{TiO}_{2}$, TUD- 1 and TUD- 1 supported $\mathrm{Cr}-\mathrm{TiO}_{2}$ samples.

may suggest the presence of $\mathrm{Cr}-\mathrm{TiO}_{2}$ nanoparticles inside the pores of TUD-1. The $\mathrm{Cr}_{-} \mathrm{TiO}_{2}$ nanoparticles influenced the formation of internal structure and pore connections in TUD-1 [25]. Meanwhile, unsupported $\mathrm{Cr}^{-} \mathrm{TiO}_{2}$ showed an isotherm between type II and IV, with an H4-type narrow hysteresis loop. BJH plot analyses demonstrated TUD-1 and Cr-TiO $/$ TUD-1 $(x)$ possessed narrow pore size distributions, strongly indicating formation of highly uniform pore systems with a mesopore size of $3.9 \mathrm{~nm}$ (Fig. 3(b)). Conversely, the unsupported $\mathrm{Cr}-\mathrm{TiO}_{2}$ exhibited a wide pore size distribution ranging from 3.5 to $8.0 \mathrm{~nm}$.

Surface areas, pore diameters, and pore volumes acquired from the sorption isotherms of the samples are listed in Table 1. TUD-1 displayed a high surface area of $924.3 \mathrm{~m}^{2} / \mathrm{g}$. A considerable decrease of surface area was observed after loading of $\mathrm{Cr}^{-\mathrm{TiO}_{2}}$ into TUD-1. Similarly, the pore volume of TUD-1 decreased remarkably in the presence of $\mathrm{Cr}^{-} \mathrm{TiO}_{2}$. These phenomena might imply the dispersion of some $\mathrm{Cr}_{-} \mathrm{TiO}_{2}$ nanoparti-
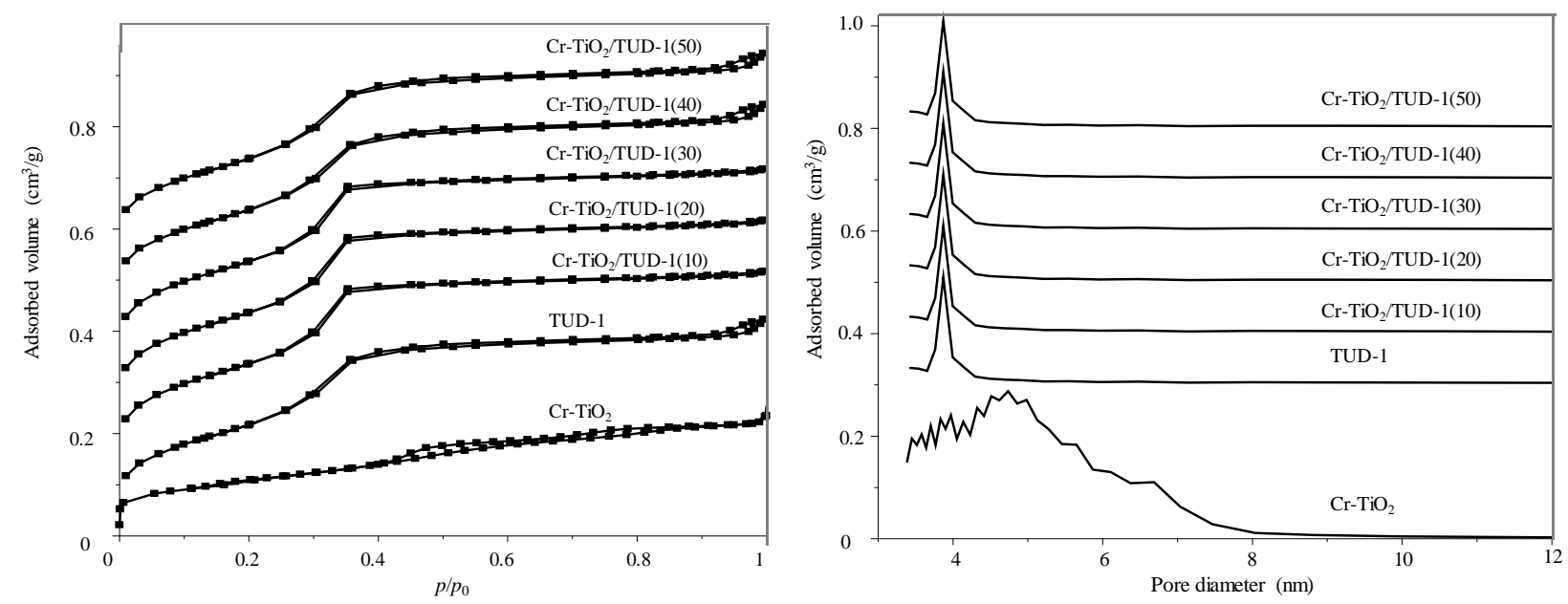

Fig. 3. (a) $\mathrm{N}_{2}$ adsorption-desorption isotherms of TUD-1 and TUD-1 supported Cr-TiO 2 samples; (b) Pore size distribution of Cr-TiO 2 , TUD-1 and TUD-1 supported $\mathrm{Cr}-\mathrm{TiO}_{2}$ samples. 
Table 1

Surface area, pore volume and pore diameter of $\mathrm{Cr}-\mathrm{TiO}_{2}$, TUD-1 and TUD-1 supported $\mathrm{Cr}-\mathrm{TiO}_{2}$ samples.

\begin{tabular}{|c|c|c|c|}
\hline Sample & $\begin{array}{c}\text { Surface area } \\
\left(\mathrm{m}^{2} / \mathrm{g}\right)\end{array}$ & $\begin{array}{c}\text { Pore volume } \\
\left(\mathrm{cm}^{3} / \mathrm{g}\right)\end{array}$ & $\begin{array}{l}\text { Pore diameter } \\
\text { (nm) }\end{array}$ \\
\hline$\overline{\mathrm{Cr}-\mathrm{TiO}_{2}}$ & 45 & 0.03 & 12.71 \\
\hline TUD-1 & 924 & 0.69 & 2.83 \\
\hline $\mathrm{Cr}-\mathrm{TiO}_{2} / \mathrm{TUD}-1(10)$ & 496 & 0.51 & 3.75 \\
\hline $\mathrm{Cr}-\mathrm{TiO}_{2} / \mathrm{TUD}-1(20)$ & 698 & 0.54 & 3.59 \\
\hline $\mathrm{Cr}-\mathrm{TiO}_{2} / \mathrm{TUD}-1(30)$ & 864 & 0.57 & 3.44 \\
\hline $\mathrm{Cr}-\mathrm{TiO}_{2} / \mathrm{TUD}-1(40)$ & 884 & 0.61 & 3.29 \\
\hline $\mathrm{Cr}^{-\mathrm{TiO}_{2}} / \mathrm{TUD}-1(50)$ & 901 & 0.64 & 3.01 \\
\hline
\end{tabular}

cles in the pores of TUD-1. These observations agree well with the XRD results (Fig 1(b)), confirming the change of TUD-1 from a well-ordered mesoporous structure to one with lowered crystallinity upon introduction of $\mathrm{Cr}_{-} \mathrm{TiO}_{2}$. The pore diameter of all the $\mathrm{Cr}_{-\mathrm{TiO}} / \mathrm{TUD}-1(\mathrm{x})$ samples was larger than that of TUD-1, and increased with $\mathrm{Cr}-\mathrm{TiO}_{2}$ content. This increase could be caused by the accumulation of $\mathrm{Cr}-\mathrm{TiO}_{2}$ around the pore mouth, resulting in enlargement of the pore width. Alternatively, the Ti-O bonds are longer than $\mathrm{Si}-\mathrm{O}$ bonds, leading to an increase in pore size. A similar phenomenon was reported for Ti-loaded TUD-1 prepared by microwave synthesis [26].

Fig. 4 shows the diffuse-reflectance UV-Vis spectra of Cr-TiO2, TUD-1, and Cr-TiO $/$ TUD-1( $x$ ) samples. All the synthesized materials exhibited absorption peaks at 250 and $330 \mathrm{~nm}$, which are assigned to tetrahedral framework $\mathrm{Ti}^{4+}$ and polytitanate (Ti-O-Ti $)_{n}$ and/or $\mathrm{TiO}_{2}$ crystals, respectively [26]. As the amount of TUD-1 in the samples increased, the peak at $330 \mathrm{~nm}$ became less intense, indicating the presence of TUD-1 facilitated formation of more tetrahedrally coordinated Ti species. The samples also showed a weak absorption at $375 \mathrm{~nm}$ that was ascribed to the electron charge transfer from $\mathrm{O}^{2-}$ to $\mathrm{Cr}^{6+}$ of tetrahedrally coordinated $\mathrm{Cr}^{6+}$ [22]. A shoulder approximately at $450 \mathrm{~nm}$ was detected for $\mathrm{Cr}_{-\mathrm{TiO}} / \mathrm{TUD}-1$ (40) and $\mathrm{Cr}_{-} \mathrm{TiO}_{2} / \mathrm{TUD}-1(50)$, implying the existence of $\mathrm{Cr}^{6+}$ polychromate $(\mathrm{Cr}-\mathrm{O}-\mathrm{Cr})_{n}$ in the titania external framework [27] originating from the large content of TUD-1 in these samples. Ab-

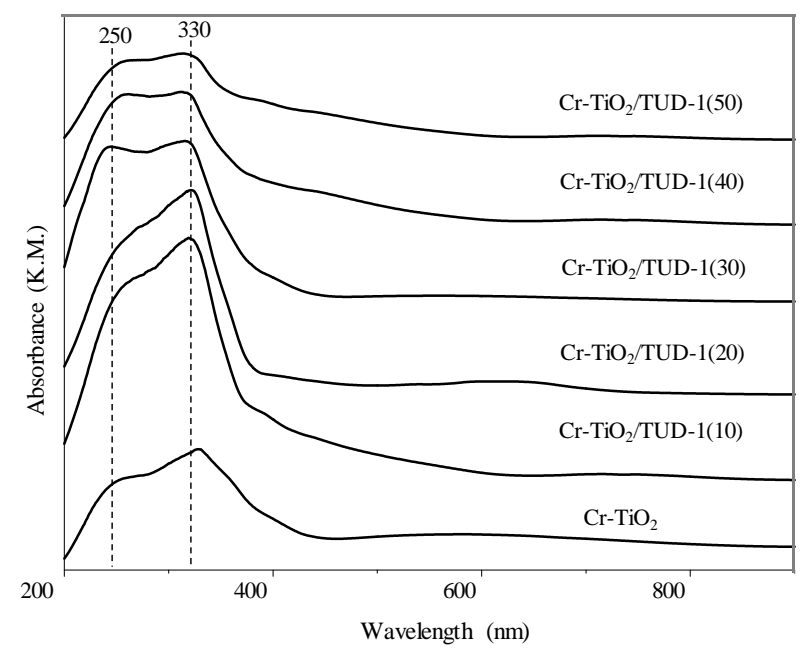

Fig. 4. DRUV-Vis spectra of $\mathrm{Cr}-\mathrm{TiO}_{2}$ and $\mathrm{TUD}-1$ supported $\mathrm{Cr}-\mathrm{TiO}_{2}$ samples.
Table 2

Band edge and band gap energy of $\mathrm{Cr}-\mathrm{TiO}_{2}$ and TUD-1 supported $\mathrm{Cr}-\mathrm{TiO}_{2}$ samples.

\begin{tabular}{|c|c|c|}
\hline Sample & Band edge $(\mathrm{nm})$ & Band gap energy $(\mathrm{eV})$ \\
\hline $\mathrm{Cr}-\mathrm{TiO}_{2}$ & 500 & 2.47 \\
\hline 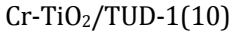 & 410 & 3.02 \\
\hline $\mathrm{Cr}^{-\mathrm{TiO}_{2} / \mathrm{TUD}-1(20)}$ & 400 & 3.10 \\
\hline $\mathrm{Cr}^{-\mathrm{TiO}_{2} / \mathrm{TUD}-1(30)}$ & 390 & 3.18 \\
\hline $\mathrm{Cr}^{-\mathrm{TiO}_{2} / \mathrm{TUD}-1(40)}$ & 380 & 3.26 \\
\hline $\mathrm{Cr}^{-\mathrm{TiO}_{2} / \mathrm{TUD}-1(50)}$ & 370 & 3.35 \\
\hline
\end{tabular}

sorption wavelengths exhibited a blue shift when a larger amount of TUD-1 was used as a support. This could be caused by the transition of Ti-O-Ti $(0.180 \mathrm{~nm})$ bonding to Si-O-Ti $(0.195 \mathrm{~nm})$ bonding, which involves formation of a longer, weaker bond [28]. As listed in Table 2, the band edge of the samples decreased with increasing TUD-1 content. The band gap energy of $\mathrm{Cr}-\mathrm{TiO}_{2}$ rose from 2.47 to $3.35 \mathrm{eV}$ after loading onto TUD-1 with Si/Ti molar ratio of 50 .

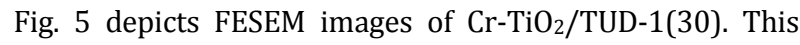
material exhibited an asymmetrical irregular sponge-like structure. Similar irregular sponge-like structure was detected for all the $\mathrm{Cr}_{-\mathrm{TiO}}$ /TUD-1( $x$ ) samples. The elemental composition of the samples was confirmed by EDX (Table 3). Both the theoretical and actual $\mathrm{Si} / \mathrm{Al}$ molar ratios for each catalyst were determined. The results indicated that the actual Si/Ti molar ratio was slightly lower than the theoretical values. The loss of Si might have occurred during the sol-gel formation process [29]. Elemental mapping using EDX was carried out for the $\mathrm{Cr}_{-} \mathrm{TiO}_{2}$ /TUD-1(30) sample (Fig. 6). The elements $\mathrm{Cr}$, Ti, 0 , and $\mathrm{Si}$ were detected. The results clearly showed that these elements were distributed homogeneously on the sample surface, suggesting the $\mathrm{Cr}-\mathrm{TiO}_{2}$ nanoparticles were well-dispersed on the TUD-1 surface. Agglomeration of $\mathrm{Cr}-\mathrm{TiO}_{2}$ nanoparticles was not detected.

TEM images of the selected material $\mathrm{Cr}_{-} \mathrm{TiO}_{2} / \mathrm{TUD}-1(30)$ are shown in Fig. 7. As illustrated in Fig. 7(a), the sample contained

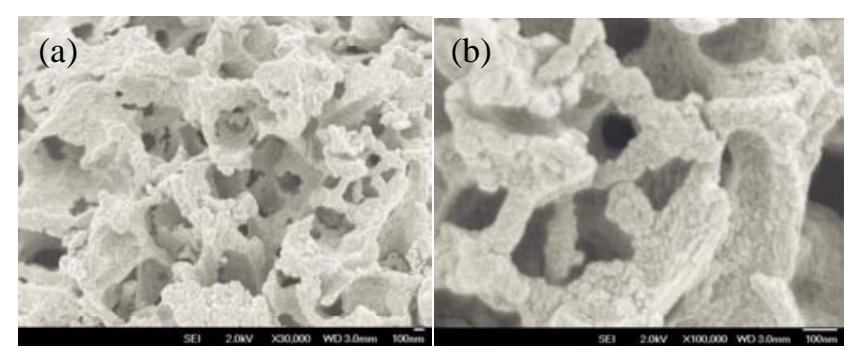

Fig. 5. FESEM images of $\mathrm{Cr}-\mathrm{TiO}_{2} / \mathrm{TUD}-1(30)$. (a) Overall morphology of at magnification $\times 30000$; (b) Detailed morphology at magnification $\times 100000$.

Table 3

EDX elemental analysis of TUD-1 supported $\mathrm{Cr}-\mathrm{TiO}_{2}$ samples.

\begin{tabular}{lcc}
\hline \multirow{2}{*}{ Sample } & Chemical composition of Si/Ti molar ratio \\
\cline { 2 - 3 } & Theoretical & Actual \\
\hline $\mathrm{Cr}^{-\mathrm{TiO}_{2}}$ /TUD-1(10) & 10 & 9.2 \\
$\mathrm{Cr}^{-\mathrm{TiO}}$ /TUD-1(20) & 20 & 18.6 \\
$\mathrm{Cr}^{-} \mathrm{TiO}_{2}$ /TUD-1(30) & 30 & 27.3 \\
$\mathrm{Cr}^{-\mathrm{TiO}_{2}}$ /TUD-1(40) & 40 & 34.8 \\
$\mathrm{Cr}^{-\mathrm{TiO}_{2}}$ /TUD-1(50) & 50 & 45.1 \\
\hline
\end{tabular}



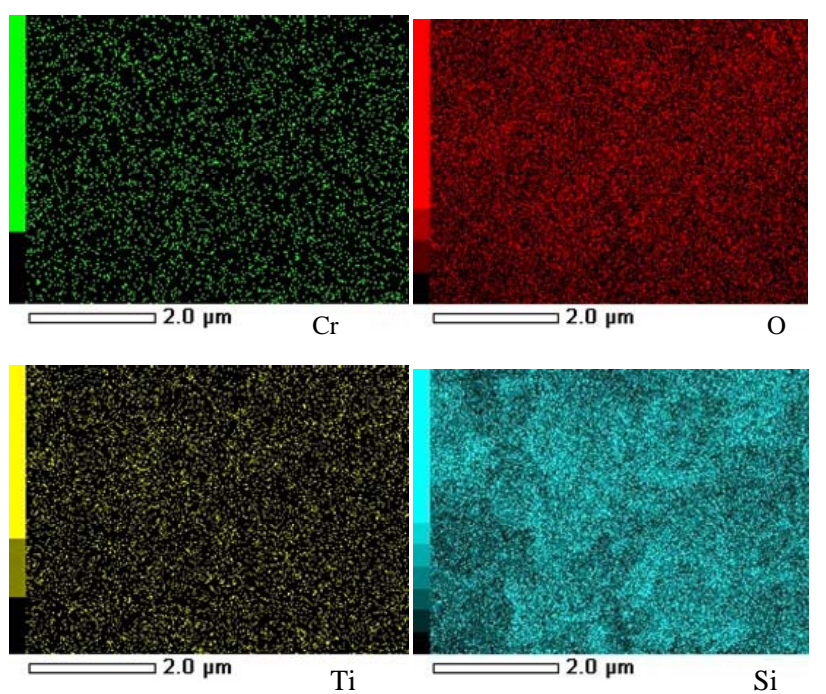

Fig. 6. EDX elemental mapping for $\mathrm{Cr}_{-} \mathrm{TiO}_{2} / \mathrm{TUD}-1(30)$.

Cr- $\mathrm{TiO}_{2}$ nanoparticles integrated inside the TUD-1 silicate matrix. The size of the nanoparticles was approximately $5 \mathrm{~nm}$. The $d$-lattice spacing of the nanoparticles was determined (Fig. 7 (b)). The obtained $d$-lattice spacing of $0.32 \mathrm{~nm}$ is consistent with the anatase phase of $\mathrm{TiO}_{2}$, implying $\mathrm{Cr}-\mathrm{TiO}_{2}$ has anatase crystal structure in the sample [30].

The sample $\mathrm{Cr}-\mathrm{TiO}_{2} / \mathrm{TUD}-1(30)$ was investigated by X-ray photoelectron spectroscopy (XPS) to identify the oxidation states of the external species. Fig. 8(a) illustrates the comprehensive XPS analysis of this sample. Species of $\mathrm{Cr}, \mathrm{Ti}, \mathrm{O}$, and $\mathrm{Si}$

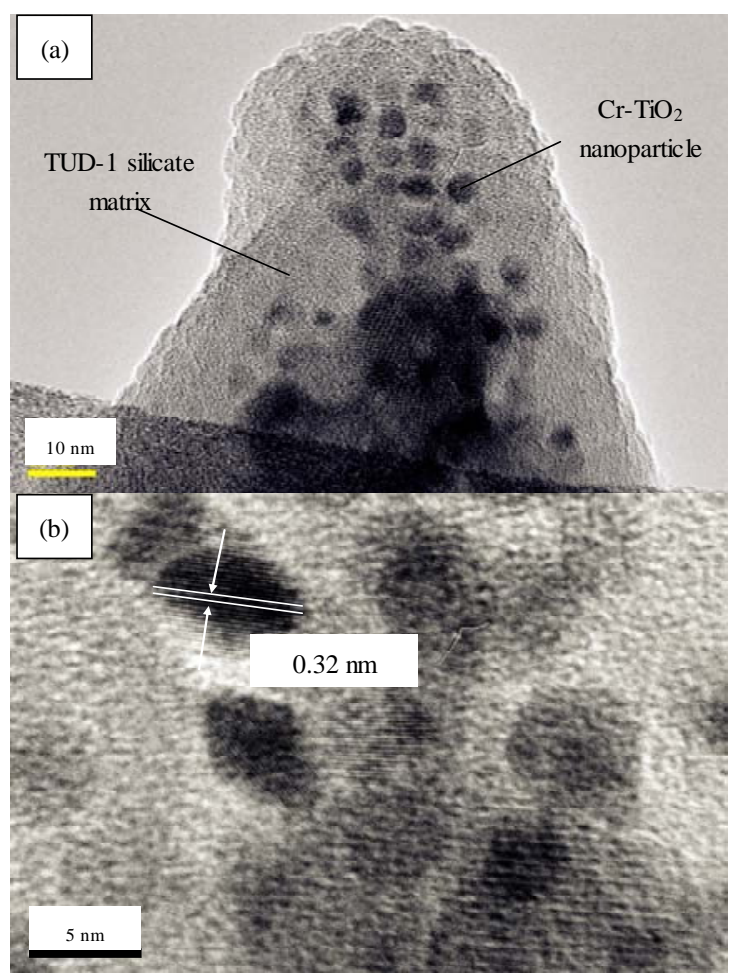

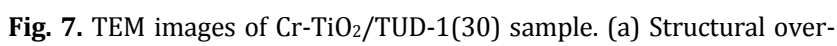
view of $\mathrm{Cr}-\mathrm{TiO}_{2} / \mathrm{TUD}-1(30)$; (b) Existence of $\mathrm{Cr}^{-\mathrm{TiO}_{2}}$ nanoparticles within TUD-1 silicate matrix.
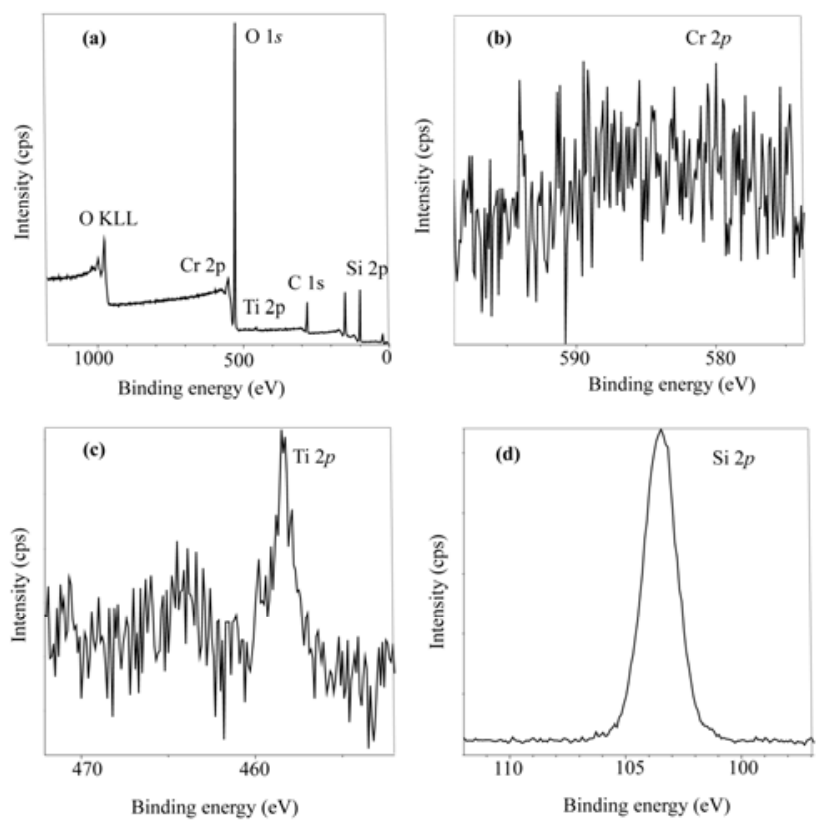

Fig. 8. XPS spectra of (a) $\mathrm{Cr}_{-}-\mathrm{TiO}_{2} / \mathrm{TUD}-1(30)$; (b) $\mathrm{Cr}$ species in Cr-TiO $/$ TUD-1(30); (c) Ti species in $\mathrm{Cr}_{-12} \mathrm{TiO}_{2} / \mathrm{TUD}-1$ (30); (d) Si species in $\mathrm{Cr}-\mathrm{TiO}_{2}$ /TUD-1(30).

were detected. The $01 s$ peak was intense because of the formation of metal oxides including $\mathrm{SiO}_{2}$, chromium oxide, and $\mathrm{TiO}_{2}$. The Si peak was attributed to the mesoporous TUD-1. The peaks from chromium oxide and $\mathrm{TiO}_{2}$ were weak because of the low loading of $\mathrm{Cr}-\mathrm{TiO}_{2}$ onto TUD-1. The detailed analysis of the chromium species is shown in Fig. 8(b). The chromium species produced a peak at a binding energy of $580 \mathrm{eV}$ with a peak area of 174.765, which may indicate the existence of $\mathrm{CrO}_{3}$ species. Therefore, it could be construed that the oxidation state of the $\mathrm{Cr}$ dopant was +6 [31]. Nonetheless, the presence of $\mathrm{Cr}$ was difficult to confirm because of its low content in the Cr-TiO $/$ TUD-1(x) samples. This could be a result of the synthesis methodology, because the $\mathrm{Cr}-\mathrm{TiO}_{2}$ nanoparticles may be embedded deep within the silicate matrix during the sol-gel process. Fig. 8(c) depicts the detailed XPS analysis of Ti. A peak assigned to $\mathrm{TiO}_{2}$ species was observed at a binding energy of $458.5 \mathrm{eV}$ with a peak area of 266.628. The result indicates that the oxidation state of the $\mathrm{TiO}_{2}$ species was +4 [32]. The comprehensive analysis for $\mathrm{Si}$ is presented in Fig. 8(d). The $\mathrm{SiO}_{2}$ species generated a peak at a binding energy of $103.5 \mathrm{eV}$ with a large peak area of 42419 . This strongly suggests that the oxidation state of the silicate was +4 [33]. This peak was intense because of the existence of silica species in the TUD-1 catalyst support, which was the main component of the samples. As listed in Table 4, Si species (38 at\%) were the most prominent species in $\mathrm{TiO}_{2} / \mathrm{TUD}-1(30)$. Meanwhile, the major species was oxygen (61.11 at\%) in the sample composed of metal/metalloid oxide.

\subsection{Adsorption of Phenol on the Photocatalyst Surface}

Prior to the photocatalytic testing, the adsorptivity of the synthesized photocatalysts was determined. The quantity of 
Table 4

Elemental composition analysis using XPS for $\mathrm{Cr}_{-} \mathrm{TiO}_{2} / \mathrm{TUD}-1(30)$.

\begin{tabular}{lc}
\hline Element & Atomic concentration $(\%)$ \\
\hline $\mathrm{O}$ & 61.11 \\
$\mathrm{Cr}$ & 0.22 \\
$\mathrm{Ti}$ & 0.67 \\
$\mathrm{Si}$ & 38.00 \\
\hline
\end{tabular}

phenol adsorbed on the catalysts was examined using UV-Vis spectroscopy. Adsorption equilibrium was achieved after $2 \mathrm{~h}$ (Fig. 9). The results demonstrated that $\mathrm{Cr}^{-} \mathrm{TiO}_{2}$ had the lowest adsorption capacity for phenol because it adsorbed only 18 $\mathrm{mg} / \mathrm{L}$ of phenol after $2 \mathrm{~h}$. Meanwhile, TUD- 1 showed the highest adsorption capacity, adsorbing $71 \mathrm{mg} / \mathrm{L}$ of phenol after $2 \mathrm{~h}$. As expected, the adsorption capacity of the $\mathrm{Cr}^{-T i O}{ }_{2} / \mathrm{TUD}-1(x)$ samples increased with TUD-1 content in the samples. The adsorption behavior was proportional to the surface area and pore volume of the samples [34].

The linearity of plots of the concentration of phenol in solution at equilibrium $C_{\mathrm{e}}(\mathrm{mg} / \mathrm{L}) /$ the amount of phenol adsorbed on the photocatalyst at equilibrium $Q_{\mathrm{e}}(\mathrm{mg} / \mathrm{g})$ versus $C_{\mathrm{e}}$ for the samples verified that the adsorption was monolayer chemisorption because it obeyed the Langmuir model, which is expressed by Equation (1) and (2) as follows.

$$
\begin{gathered}
Q_{\mathrm{e}}=\left(C_{0}-C_{\mathrm{e}}\right) V / m \\
C_{\mathrm{e}} / Q_{\mathrm{e}}=\left(1 / Q_{\mathrm{m}}\right) C_{\mathrm{e}}+1 / K_{\mathrm{L}} Q_{\mathrm{m}}
\end{gathered}
$$

where $C_{0}$ is the initial concentration of phenol in solution (mg/L), $V$ is the volume of phenol solution (L), $m$ is the mass of photocatalyst used (g), $K_{\mathrm{L}}$ is the Langmuir adsorption constant (L/mg), and $Q_{\mathrm{m}}$ is the maximum adsorption capacity $(\mathrm{mg} / \mathrm{g}$ ). Table 5 gives $Q_{\mathrm{m}}$ of all the samples. The adsorption capacity of $\mathrm{Cr}-\mathrm{TiO}_{2}$ was enhanced substantially (more than 2.5 fold) after loading onto TUD-1.

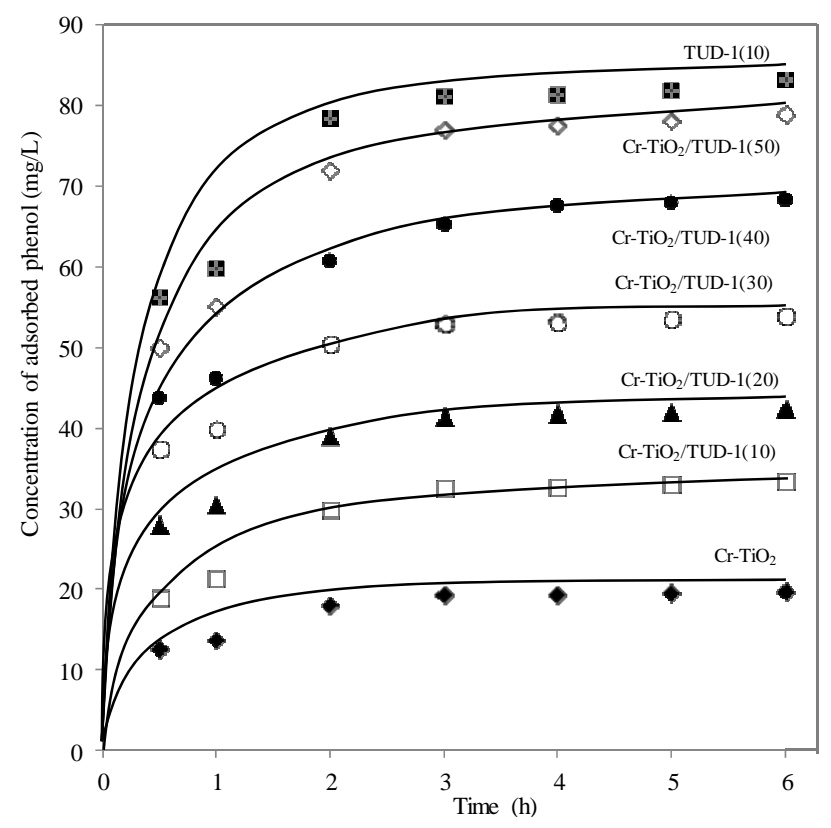

Fig. 9. Adsorptivity equilibrium plot for $\mathrm{Cr}_{-} \mathrm{TiO}_{2}$ and $\mathrm{Cr}_{-} \mathrm{TiO}_{2} / \mathrm{TUD}-1(x)$ samples.
Table 5

Kinetics data obtained from Langmuir model fitting plot for $\mathrm{Cr}^{-} \mathrm{TiO}_{2}$ and

\begin{tabular}{|c|c|c|}
\hline Photocatalyst & $R^{2}$ & $Q_{\mathrm{m}}(\mathrm{mg} / \mathrm{g})$ \\
\hline $\mathrm{Cr}-\mathrm{TiO}_{2}$ & 0.9941 & 0.63 \\
\hline $\mathrm{Cr}-\mathrm{TiO}_{2} / \mathrm{TUD}-1(10)$ & 0.9909 & 1.63 \\
\hline $\mathrm{Cr}-\mathrm{TiO}_{2} / \mathrm{TUD}-1(20)$ & 0.9951 & 3.02 \\
\hline $\mathrm{Cr}-\mathrm{TiO}_{2} / \mathrm{TUD}-1(30)$ & 0.9970 & 5.12 \\
\hline $\mathrm{Cr}-\mathrm{TiO}_{2} / \mathrm{TUD}-1(40)$ & 0.9943 & 7.54 \\
\hline $\mathrm{Cr}-\mathrm{TiO}_{2} / \mathrm{TUD}-1(50)$ & 0.9942 & 10.06 \\
\hline TUD-1 & 0.9977 & 11.79 \\
\hline
\end{tabular}
$\mathrm{Cr}^{-\mathrm{TiO}_{2}}$ /TUD-1 $(x)$ sample.

\subsection{Photocatalytic Testing}

The photocatalytic performance of all the synthesized photocatalysts was evaluated through phenol photodegradation experiments (Fig. 10). The results indicated that $\mathrm{Cr}-\mathrm{TiO}_{2}$ was an active photocatalyst for phenol photodegradation, photodegrading $66 \mathrm{mg} / \mathrm{L}$ phenol after $5 \mathrm{~h}$ reaction under visible light irradiation. It has been reported that $\mathrm{Cr}-\mathrm{TiO}_{2}$ is an effective photocatalyst for dye photodegradation under visible light [8]. Conversely, TUD-1 was totally inactive in photodegradation of phenol. Even though TUD-1 possessed high surface area and pore volume, it did not have active sites for the photocatalytic reaction. After introducing $\mathrm{Cr}_{-} \mathrm{TiO}_{2}$ into the TUD-1 support, the photocatalytic activity of $\mathrm{Cr}_{-}-\mathrm{TiO}_{2}$ improved remarkably.

It is believed that the stable mesoporous structure of TUD-1 provided high accessibility to nearly all $\mathrm{Cr}-\mathrm{TiO}_{2}$ nanoparticles and raised the photocatalytic reactivity of $\mathrm{Cr}-\mathrm{TiO}_{2}$ by supplying more active sites to adsorb phenol and hydroxyl groups. In addition, the high surface area of TUD-1 could have acted like a sponge to pre-concentrate the phenol reactant on the photocatalyst surface, increasing the availability of phenol and making it accessible to the active sites on the TUD-1 support surface [35]. More importantly, the current results strongly suggest that TUD-1 played an important role as a support to ensure the $\mathrm{Cr}_{-} \mathrm{TiO}_{2}$ nanoparticles were well distributed and not agglomer-

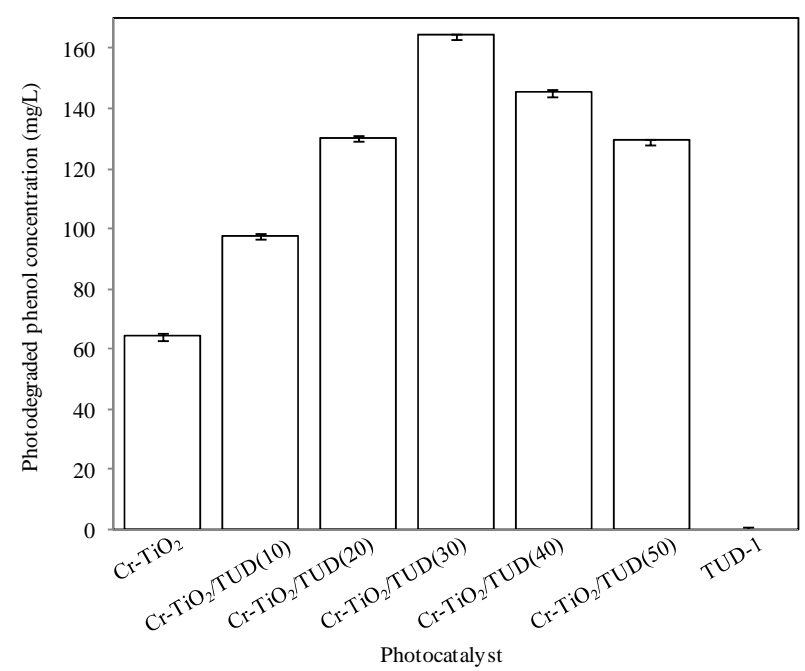

Fig. 10. Photocatalytic performance of $\mathrm{Cr}-\mathrm{TiO}_{2}$ and TUD-1 supported $\mathrm{Cr}-\mathrm{TiO}_{2}$ samples. 


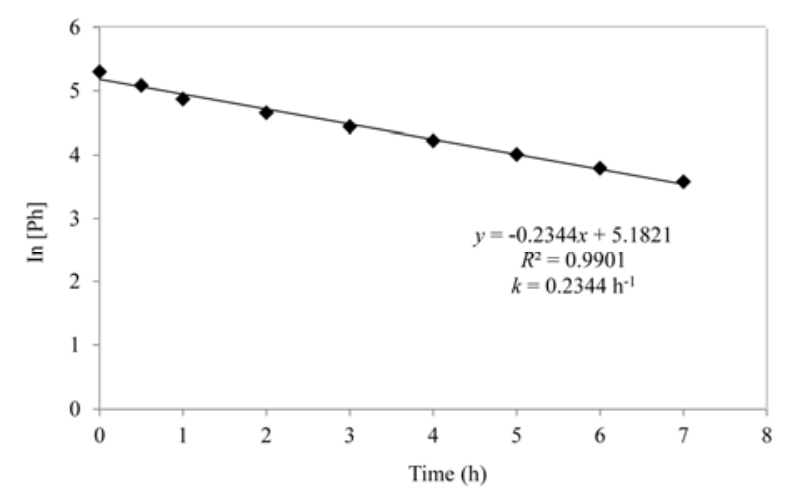

Fig. 11. The kinetic plot of phenol photodegradation using Cr-TiO $/$ TUD-1(30) photocatalyst.

ated, as evidenced in the EDX mapping images. Furthermore, the $\mathrm{Si}-\mathrm{O}-\mathrm{Ti}$ bonds in the silica framework of TUD- 1 might have acted as active sites for the photodegradation reaction. Consequently, the photocatalytic performance of $\mathrm{Cr}^{-} \mathrm{TiO}_{2}$ supported on TUD-1 was enhanced markedly compared with that of unsupported $\mathrm{Cr}_{-} \mathrm{TiO}_{2}$. Amongst the samples, $\mathrm{Cr}_{-} \mathrm{TiO}_{2} / \mathrm{TUD}-1(30)$ showed the highest photocatalytic activity (Fig. 10), photodegrading $162 \mathrm{mg} / \mathrm{L}$ phenol after $5 \mathrm{~h}$ of photocatalytic reaction.

\subsubsection{Reaction order and kinetic rate}

The reaction order and rate of $\mathrm{Cr}_{-} \mathrm{TiO}_{2} / \mathrm{TUD}-1(30)$ were determined. Fig. 11 shows that phenol photodegradation using Cr-TiO $/$ TUD-1(30) was a first-order reaction according to the following equations.

$$
\begin{gathered}
\ln [\mathrm{Ph}]_{t}=-k t+\ln [\mathrm{Ph}]_{0} \\
\text { rate }=k[\mathrm{Ph}]
\end{gathered}
$$

where $[\mathrm{Ph}]_{t}$ is the concentration of phenol at time $t, k$ is the rate constant, and $[\mathrm{Ph}]_{0}$ is the initial concentration of phenol. A negative linear plot was obtained when $\ln [\mathrm{Ph}]$ was plotted against $t$. Thus, the photocatalytic reaction depended solely on phenol concentration and the reaction rate was $0.2344 \mathrm{~h}^{-1}$.

\subsubsection{Effect of initial phenol concentration on photocatalytic performance}

Initial phenol concentration is a critical factor in any water treatment procedure. The effect of initial phenol concentration on photocatalytic performance was studied in the range of

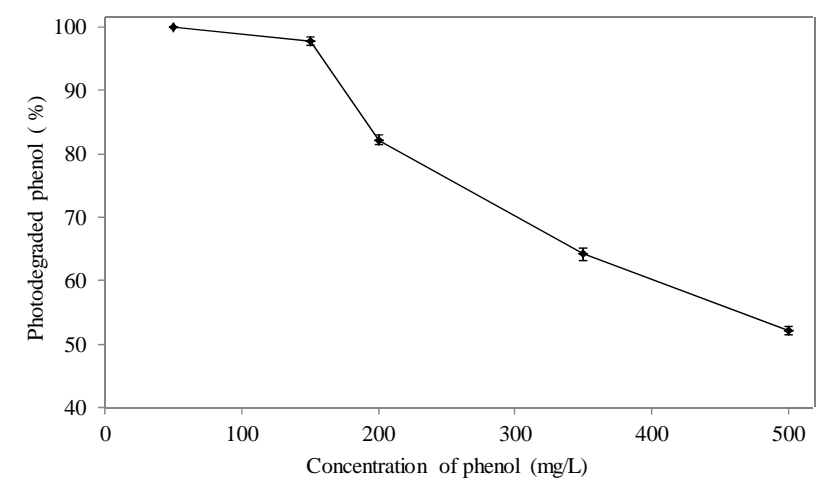

Fig. 12. Effect of initial concentration of phenol.
$50-500 \mathrm{mg} / \mathrm{L}$ in the presence of $0.1 \mathrm{~g} \mathrm{Cr}-\mathrm{TiO}_{2} / \mathrm{TUD}-1(30)$ photocatalyst at $\mathrm{pH}=7$; the results are shown in Fig. 12 . With increasing phenol concentration, less phenol was photodegraded under otherwise identical reaction conditions. It is believed that at high initial phenol concentration, the amount of phenol

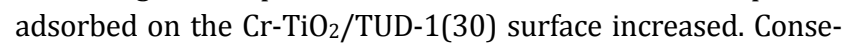
quently, the formation of hydroxyl radicals was hindered because of the limited number of active sites available to adsorb superoxide ions [36]. Furthermore, a high aqueous-phase phenol concentration might lessen the visible light irradiation of the photocatalyst surface, which would decrease photoabsorption, resulting in an appreciable decrease in phenol photodegradation.

\subsubsection{Effect of photocatalyst amount on photocatalytic performance}

The effect of $\mathrm{Cr}-\mathrm{TiO}_{2} / \mathrm{TUD}-1(30)$ quantity on phenol photodegradation was determined using phenol solutions with a concentration of $200 \mathrm{mg} / \mathrm{L}$ at $\mathrm{pH}=7$ (Fig. 13). The findings confirmed the positive effect of the increasing number of active sites of photocatalyst on the photodegradation kinetics up to a certain point. The highest photodegradation was achieved when $0.1 \mathrm{~g}$ of $\mathrm{Cr}-\mathrm{TiO}_{2} / \mathrm{TUD}-1(30)$ was used. A further increase in photocatalyst dosage resulted in decreased photodegradation performance. As the photocatalyst amount increased, so did the total active surface sites for light absorption. Therefore, the amount of hydroxyl and/or superoxide radicals increased, leading to improved photocatalytic activity [32]. However, system turbidity increased with photocatalyst content. The increase of opacity and light scattering of $\mathrm{Cr}^{-\mathrm{TiO}_{2} / \mathrm{TUD}-1(30)}$ particles with their content in the reaction mixture would result in decreased transmittance of irradiation passing through the photocatalyst, thus lowering the photocatalytic activity [37]. In addition, photocatalyst aggregation when a large quantity of catalyst was present would cause the amount of surface active sites to decrease.

\subsubsection{Effect of $\mathrm{pH}$ on photocatalytic performance}

Phenol photodegradation occurs on the surface of the photocatalyst, so $\mathrm{pH}$ plays an important role in degradation performance. At alkaline $\mathrm{pH}$, the catalyst surface becomes negatively charged, while the surface becomes positively charged at acidic $\mathrm{pH}$. Therefore, $\mathrm{pH}$ plays a pivotal role in the surface ad-

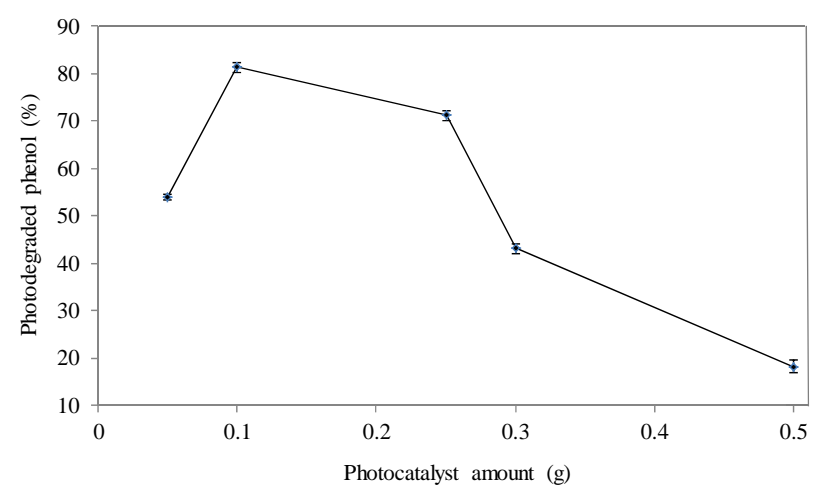

Fig. 13. Effect of amount of $\mathrm{Cr}-\mathrm{TiO}_{2} / \mathrm{TUD}-1(30)$ photocatalyst. 


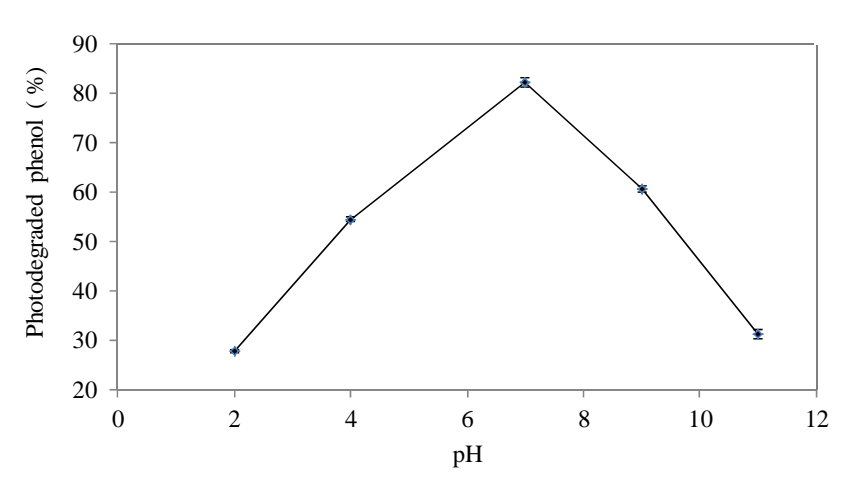

Fig. 14. Effect of $\mathrm{pH}$ in photodegradation of phenol.

sorption-desorption characteristics of a photocatalyst [38]. The effect of $\mathrm{pH}$ on phenol (200 $\mathrm{mg} / \mathrm{L})$ photodegradation using 0.1 g Cr- $\mathrm{TiO}_{2}$ /TUD-1(30) photocatalyst is illustrated in Fig. 14. The results demonstrate that the photocatalyst achieved the highest activity for phenol photodegradation at $\mathrm{pH}=7$ after $5 \mathrm{~h}$ reaction, degrading $82 \%$ of the phenol in the solution. The photocatalytic activity of the photocatalyst decreased dramatically at both low and high pH. At low pH (acidic), the positively charged surface repelled the phenol reactant, thus lowering the surface adsorptivity of the photocatalyst. Meanwhile, at high pH (alkaline), the photocatalyst coagulated, thus decreasing the availability of the surface active sites [39].

The zeta potential curve of $\mathrm{Cr}-\mathrm{TiO}_{2} / \mathrm{TUD}-1(30)$ in phenol solution was plotted (Fig. 15(a)). The surface charge of $\mathrm{Cr}_{-} \mathrm{TiO}_{2} / \mathrm{TUD}-1(30)$ is influenced by the $\mathrm{pH}$ of the phenol solution. The $\mathrm{pH}$ at zero point charge $\mathrm{pH}_{\mathrm{zpc}}$ of $\mathrm{Cr}-\mathrm{TiO}_{2} / \mathrm{TUD}-1(30)$ is approximately 6.7. Therefore, the surface is positively charged when the $\mathrm{pH}$ of the phenol solution is lower than $\mathrm{pH}_{\mathrm{zpc}}$ and vice versa. Fig. 15(b) plots of the amount of phenol adsorbed versus
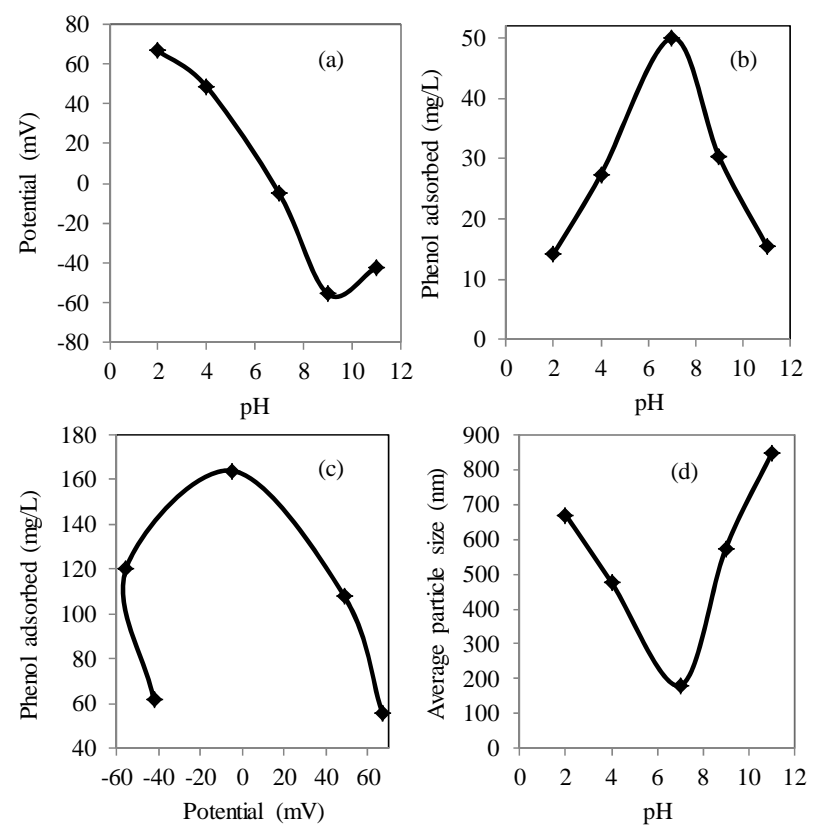

Fig. 15. Effect of $\mathrm{pH}$ on zeta potential, adsorptivity and average particle size of $\mathrm{Cr}-\mathrm{TiO}_{2}$ /TUD-1(30) in phenol suspension.
$\mathrm{pH}$. The maximum amount of phenol was adsorbed at neutral $\mathrm{pH}$, which is very close to $\mathrm{pH}_{\mathrm{zpc}}$. Because phenol is non-ionic, the effect of surface charge on $\mathrm{Cr}_{-} \mathrm{TiO}_{2} / \mathrm{TUD}-1(30)$ towards the adsorptivity of phenol is indirect. As shown in Fig. 15(c), the amount of phenol adsorbed decreased with increasing zeta potential when the potential was greater than $+20 \mathrm{mV}(\mathrm{pH}$ approximately equal to 6). The optimum adsorption of phenol was recorded at zeta potential ranging from -5 to $0 \mathrm{mV}$. When the zeta potential was lower than $-40 \mathrm{mV}$ ( $\mathrm{pH}$ of approximately 8), the amount of phenol adsorbed decreased with decreasing zeta potential. Such features indicate that electrostatic interactions between the charged surface and phenol are negligible and are primarily dispersion forces. In other words, strong electrostatic repulsion forces tended to push the phenol away from the surface and decreased the dispersion forces between phenol and the $\mathrm{Cr}_{-} \mathrm{TiO}_{2} / \mathrm{TUD}-1(30)$ surface when the Cr-TiO $/$ TUD-1(30) surface was positively or negatively charged. As a result, the surface adsorption forces of Cr-TiO $/$ TUD-1(30) decreased at low or high pH. Fig. 15(d) illustrates the average particle size of $\mathrm{Cr}-\mathrm{TiO}_{2} / \mathrm{TUD}-1(30)$ in phenol solutions of different $\mathrm{pH}$. Cr-TiO $/$ TUD-1(30) possessed the smallest average particle size when the $\mathrm{pH}$ was close to $\mathrm{pH}_{\text {zpc. }}$ Meanwhile, the average particle size of $\mathrm{Cr}_{-} \mathrm{TiO}_{2} / \mathrm{TUD}-1(30)$ increased markedly at extremely low and high $\mathrm{pH}$. This implies that the particles of $\mathrm{Cr}_{-} \mathrm{TiO}_{2} / \mathrm{TUD}-1(30)$ tended to agglomerate at low and high $\mathrm{pH}$, causing particle growth because of the strong electrostatic forces at the catalyst surface.

\subsubsection{Reusability of the photocatalyst}

The reusability of $\mathrm{Cr}_{-} \mathrm{TiO}_{2} / \mathrm{TUD}-1(30)$ for three cycles was investigated; the results are shown in Fig. 16. For comparison, the reusability of $\mathrm{Cr}-\mathrm{TiO}_{2} / \mathrm{MCM}-41$ with the same $\mathrm{Si} / \mathrm{Ti}$ molar ratio $=30$ was also tested under the same reaction conditions. In each cycle, the photocatalyst was reused for the photodegradation of a fresh phenol solution. The initial concentration of phenol was constant $(200 \mathrm{mg} / \mathrm{L})$, and solutions were irradiated for $5 \mathrm{~h}$. The photocatalyst was recycled after being centrifuged, washed, and calcined at $723 \mathrm{~K}$ for $4 \mathrm{~h}$ after every photodegra-

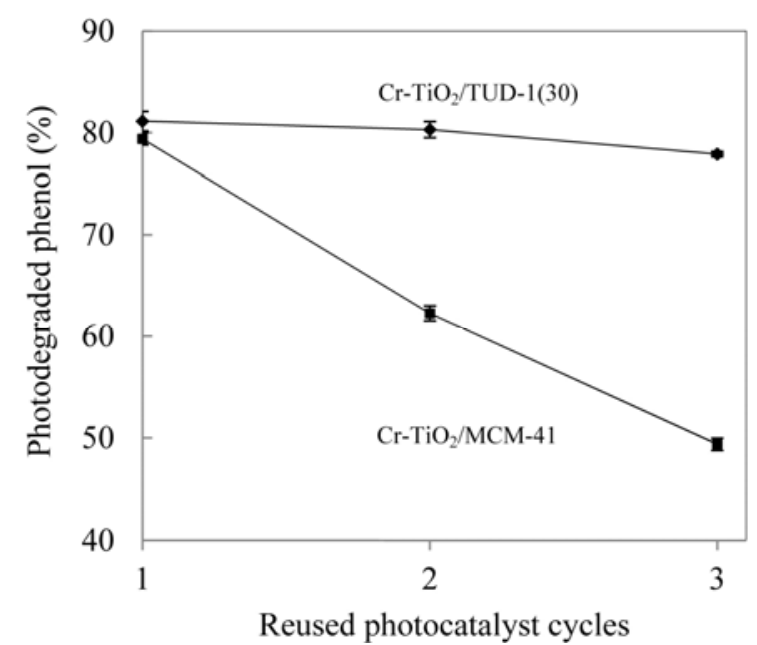

Fig. 16. Reusability of the $\mathrm{Cr}-\mathrm{TiO}_{2} / \mathrm{TUD}-1(30)$ and $\mathrm{Cr}-\mathrm{TiO}_{2} / \mathrm{MCM}-41$. 
dation measurement. After three cycles, $\mathrm{Cr}_{-} \mathrm{TiO}_{2} / \mathrm{TUD}-1(30)$ was still effective for the photodegradation of phenol, with negligible decrease $(<3 \%)$ in the photodegradation percentage of phenol. The small decrease in photocatalytic performance might be attributed to photocatalyst aggregation after several calcination steps, which would lower the surface area of the material. Conversely, $\mathrm{Cr}-\mathrm{TiO}_{2} / \mathrm{MCM}-41$ exhibited substantial photocatalytic deactivation after the first run. This may be because the one-dimensional pore channel of MCM-41 does form a good physical interaction with $\mathrm{Cr}-\mathrm{TiO}_{2}$ nanoparticles, resulting in leaching that decreased the photocatalytic activity of the material [40]. While the phenol solution remained colorless after the photocatalytic reaction using $\mathrm{Cr}_{-} \mathrm{TiO}_{2} / \mathrm{TUD}-1(30)$ photocatalyst, it turned into pale yellow after the photocatalytic reaction using $\mathrm{Cr}_{-} \mathrm{TiO}_{2} / \mathrm{MCM}-41$, implying $\mathrm{Cr}$ leaching in the latter sample. These findings strongly indicate that TUD-1 is a better $\mathrm{Cr}-\mathrm{TiO}_{2}$ photocatalyst support than MCM-41 for phenol degradation.

\section{Conclusions}

Mesoporous $\mathrm{Cr}-\mathrm{TiO}_{2} / \mathrm{TUD}-1(x)$ samples, where $x=10-50$, were excellent photocatalysts for phenol photodegradation under visible light irradiation. The mesoporous structure of these catalysts was evidenced by XRD and adsorption-desorption analyses. $\mathrm{Cr}-\mathrm{TiO}_{2} / \mathrm{TUD}-1(x)$ samples possessed high surface areas and narrow distributions of pore size diameter. The photocatalytic testing results demonstrated that these materials exhibited higher activity in the photodegradation of phenol than unsupported $\mathrm{Cr}-\mathrm{TiO}_{2}$. $\mathrm{Cr}-\mathrm{TiO}_{2} / \mathrm{TUD}-1(30)$ showed the highest photocatalytic activity in phenol photodegradation, achieving $82 \%$ conversion. Photocatalysis followed the Langmuir adsorption isotherm and first-order kinetics with a rate of $0.2344 \mathrm{~h}^{-1}$. Because of its high reusability, $\mathrm{Cr}^{-\mathrm{TiO}_{2}}$ /TUD-1(30) shows potential as a photocatalyst for phenol degradation under visible light irradiation.

\section{Acknowledgments}

The authors gratefully acknowledge the Ministry of Higher Education, Malaysia and Universiti Teknologi Malaysia (UTM) for the financial supports through Research University Grants (Q.J130000.2426.03G35 and Q.J130000.2526.10H54). Y.K. Ooi acknowledges the UTM Post Doctoral Fellowship Award provided by UTM.

\section{References}

[1] L. L. Zhang, Z. P. Xing, H. Zhang, Z. Z. Li, X. Y. Wu, X. D. Zhang, Y. Zhang, W. Zhou, Appl. Catal. B, 2016, 180, 521-529.

[2] Z. P. Xing, Z. Z. Li, X. Y. Wu, G. F. Wang, W. Zhou, Int. J. Hydrogen Energy, 2016, 41, 1535-1541.

[3] H. Zhang, Z. P. Xing, Y. Zhang, Z. Z. Li, X. Y. Wu, C. T. Liu, Q. Zhu, W. Zhou, RSC Adv., 2015, 5, 107150-107157.

[4] L. L. Zhang, Z. P. Xing, H. Zhang, Z. Z. Li, X. D. Zhang, Y. Zhang, L. Li, W. Zhou, ChemPlusChem, 2015, 80, 623-629.

[5] Z. P. Xing, W. Zhou, F. Du, L. L. Zhang, Z. Z. Li, H. Zhang, W. Li, ACS Appl. Mater. Interfaces, 2014, 6, 16653-16660.
[6] M. Antonopoulou, D. Hela, I. Konstantinou, Sci. Total Environ., 2016, 545-546, 476-485.

[7] N. A. Mir, A. Khan, M. Muneer, S. Vijayalakhsmi, Sci. Total Environ., 2013, 458-460, 388-398.

[8] K. Liu, J. H. Lu, Y. F. Ji, Water Res., 2015, 84, 1-7.

[9] J. D. Ye, X. B. Li, J. G. Hong, J. Q. Chen, Q. H. Fan, Mater. Sci. Semicon. Process., 2015, 39, 17-22.

[10] J. Z. Xiao, R. H. Tao, B. F. O. Costa, J. A. Paixao, Mater. Today, 2015, 2,141-146.

[11] M. Vranjes, Z. V. Saponjic, L. S. Zivkovic, V. N. Despotovic, D. V. Sojic, B. F. Abramovic, M. I. Comor, Appl. Catal. B, 2014, 160-161, 589-596.

[12] G. N. Shao, S. M. Imran, S. J. Yeon, S. J. Kang, S. M. Haider, H. T. Kim, App. Surf. Sci, 2015, 351, 1213-1223.

[13] P. W. Koh, L. Yuliati, H. O. Lintang, S. L. Lee, Aust. J. Chem., 2015, 68, 1129-1135.

[14] M. S. Hamdy, G.Mul, Appl. Catal. B, 2015, 174-175, 413-420.

[15] H. Hamdan, M. N. M. Muhid, S. L. Lee, Y.Y. Tan. Int. J. Chem. React. Eng., 2009, 7, Article 4.

[16] M. Anpo, H. Yamashita, K. Ikeue, Y. Fujii, S. G. Zhang, Y. Ichihashi, D. R. Park, Y. Suzuki, K. Koyano, T. Tatsumi, Catal. Today, 1998, 44, 327-332.

[17] Y. K. Ooi, L. Yuliati, S. L. Lee, J. Teknol., 2014, 69, 81-86.

[18] Y. K. Ooi, L. Yuliati, S. L. Lee, Adv. Mater. Res., 2015, 1109, 424-428.

[19] T. Heikkilae, J. Salonen, J. Tuura, M. S. Hamdy, G. Mul, N. Kumar, T. Salmi, D. Yu. Murzin, L. Laitinen, A. M. Kaukonen, J. Hirvonen, V. P. Lehto, Int. J. Pharm., 2013, 331, 133-138.

[20] L. Li, D. Cani, P. P. Pescarmona, Inorg. Chim. Acta, 2015, 431, 289-296.

[21] E. A. Alarcón, A. L. Villa',C. M. de Correa, Microporous Mesoporous Mater., 2009, 122, 208-215.

[22] Y. H. Shu, Y. M. Shao, X. Y. Wei, X. Wang, Q. Q. Sun, Q. Y. Zhang, L. S. $\mathrm{Li}$, Microporous Mesoporous Mater., 2015, 214, 88-94.

[23] P. L. Llewellyn, Y. Grillet, F. Schüth, H. Reichert, K. K. Unger, Microporous Mater.1994, 3, 345-349.

[24] J. Y. Fu, P. Zheng, P. Du, A. J. Duan, Z. Zhao, G. Y. Jiang, J. Liu, Y. C. Wei, C. M. Xu, K. B. Chi, Appl. Catal. A, 2015, 502, 320-328.

[25] S. M. Jeong, A. Burri, N. Z. Jiang, S. E. Park, Appl. Catal. A, 2014, 476, $39-44$.

[26] S. L. Lee, S. C. Wei, H. Nur, H. Hamdan, Int. J. Chem. React. Eng., 2010, 8, A63

[27] Y. L. Gu, M. X. Yin, H. M. Zhang, Y. Q. Wang, J. H. Shi, Spectrochim. Acta A, 2015, 136, 1702-1709.

[28] I. Blate, R. J. Pugh, J. van de Pas, I. Callaghan, J. Colloid Interf. Sci., 2009, 336, 584-591.

[29] P. Chowdhury, J. Moreira, H. Gomma, A. K. Ray, Ind. Eng. Chem. Res., 2012, 51, 4523-4532.

[30] N. Barka, I. Bakas, S. Qourzal, A. Assabbane, Y. Ait-Ichou, Orient. J. Chem., 2013, 29, 1055-1060.

[31] V. Murphy, S. A. M. Tofail, H. Hughes, P. McLoughlin, Chem. Eng. J., 2009, 148, 425-433.

[32] Z. D. Davis, B. J. Tatarchuk, Appl. Surf. Sci., 2015, 353, 679-685.

[33] E. Vanea, V. Simon, Appl. Surf. Sci., 2013, 280, 144-150.

[34] R. A. Shawabkeh, O. A. Kashman, G. I. Bisharat, Int. J. Chem., 2010, 2, 10-18.

[35] M. Najam Khan, J. Dutta, Mater. Sci. Semicon. Process., 2015, 36, 124-133.

[36] Z. J. Wu, W. Huang, K. K. Cui, Z. F. Gao, P. Wang, J. Hazard. Mater., 2014, 278, 91-99.

[37] Y. H. Shu, Y. M. Shao, X. Y. Wei, X. Wang, Q. Q. Sun, Q. Y. Zhang, L. S. $\mathrm{Li}$, Microporous Mesoporous Mater., 2015, 214, 88-94.

[38] B. E. Castillo-Reyes, V. M. Ovando-Medina, O. Gonzalez-Ortega, P. 


\section{Graphical Abstract}

Chin. J. Catal., 2016, 37: 1871-1881 doi: 10.1016/S1872-2067(16)62492-0

Phenol photocatalytic degradation over mesoporous TUD-1-supported chromium oxide-doped titania photocatalyst

Yee Khai Ooi, Leny Yuliati, Siew Ling Lee*

Universiti Teknologi Malaysia

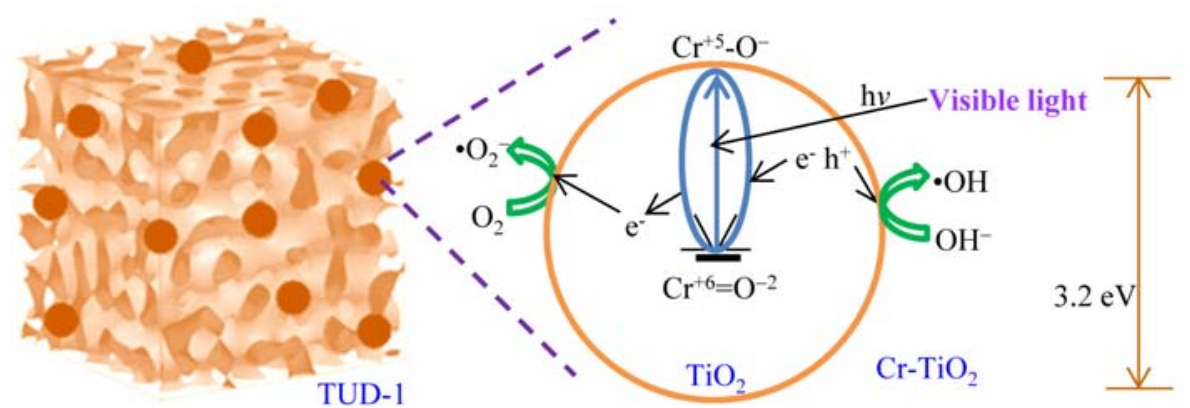

The excellent photoactivity of $\mathrm{Cr}_{-} \mathrm{TiO}_{2} / \mathrm{TUD}-1$ was contributed by high redox capabilities of $\mathrm{Cr}^{6+} \mathrm{dopant}$ and $\mathrm{Ti}^{4+}$. The high surface area of TUD-1 has improved adsorptivity of phenol, hence enhanced diffusivity towards the active sites.

A. Alonso-Pavila, I. Juarez-Ramirez, H. Matinez-Gutlernez, A. Marquez-Herrera, Catal. Lett., 2014, 41, 8211-8231.

[39] M. Safari, R. Talebi, M. H. Rostami, M. Nikazar, M. Dadvar, J. Envi- ron. Health Sci. Eng., 2014, 12, 19-27.

[40] Y. K. Ooi, L. Yuliati, D. Hartanto, H. Nur, S. L. Lee, Micro. Meso. Mater., 2016, 225, 411-420.

\section{中孔TUD负载的氧化铬掺杂氧化钛光催化降解苯酚 \\ Yee Khai Ooi ${ }^{\text {a }}$, Leny Yuliati ${ }^{\mathrm{b}}$, Siew Ling Lee ${ }^{\mathrm{a}, \mathrm{b}, *}$ \\ 马马来西亚工艺大学理学院化学系, 新山81310, 马来西亚 \\ b马来西亚工艺大学科学与工业研究所, 可持续纳米材料中心, 新山81310, 马来西亚}

摘要: 中孔的TUD-1负载的氧化铬掺杂 $\mathrm{TiO}_{2}\left(\mathrm{Cr}-\mathrm{TiO}_{2}\right)$ 有望用于紫外光照射下光催化降解苯酚的催化剂. 低角X射线衍射和 红外结果证实该样品中TUD-1存在无定形和中孔硅酸盐框架. TUD-1的中孔结构进一步得到 $\mathrm{N}_{2}$ 吸附-脱附的证实：为IV型 等温线, 并具有窄的孔径分布 $(3.9 \mathrm{~nm})$ 和高的比表面积 $\left(>490 \mathrm{~m}^{2} / \mathrm{g}\right)$. 透射电镜结果表明, 所制样品保持了纳米颗粒和多孔 孔道结构. TUD-1中负载Cr- $\mathrm{TiO}_{2}$ 后使得带隙能量增加. 与未负载的 $\mathrm{Cr}-\mathrm{TiO}_{2}$ 相比, 所有 $\mathrm{TUD}-1$ 负载的 $\mathrm{Cr}-\mathrm{TiO}_{2}$ 光催化剂表现 出更高的紫外光下降解苯酚的活性. 其中 $\mathrm{Si} / \mathrm{Ti}$ 摩尔比为 30 的 $\mathrm{Cr}-\mathrm{TiO}_{2} / \mathrm{TUD}-1$ 样品的光催化活性最高(82\%). 苯酚的光催化 降解遵循一级Langmuir吸附等温线.

关键词: 苯酚; TUD-1; 二氧化钛; 光催化剂; 中孔

收稿日期: 2016-07-28. 接受日期: 2016-08-21. 出版日期: 2016-11-05.

*通讯联系人. 电话: +607-5536039; 传真: +607-5536080; 电子信箱: sllee@ibnusina.utm.my

本文的英文电子版由Elsevier出版社在ScienceDirect上出版(http://www.sciencedirect.com/science/journal/18722067). 